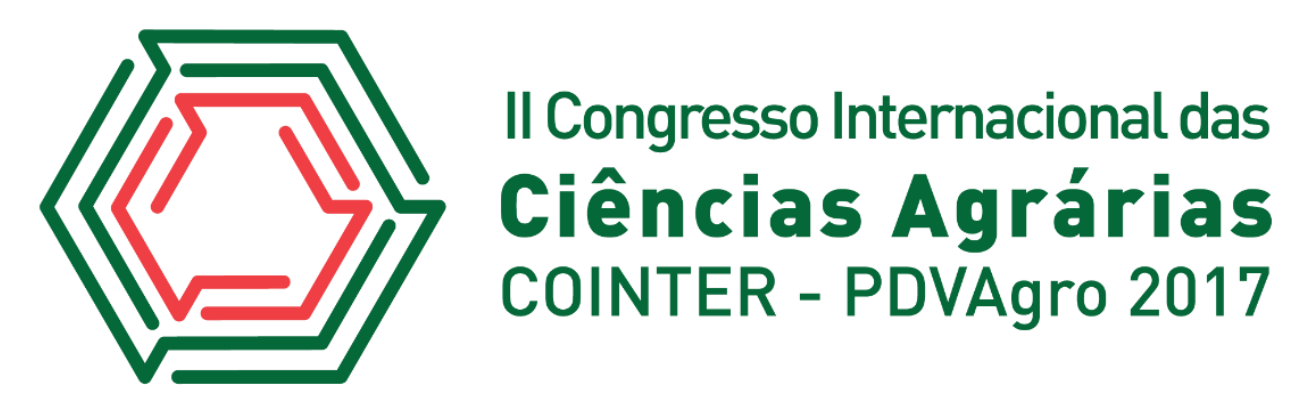

\title{
ORIENTAÇÃO TÉCNICA A AGRICULTORES FAMILIARES EM MANEJO E PRODUÇÃO DE SUÍNOS
}

\author{
Apresentação: Pôster
}

\begin{abstract}
Tielle da Luz Tavares ${ }^{1}$; Raquel da Silva Lima ${ }^{2}$; Claudenilde de Jesus Pinheiro Costa ${ }^{3}$; Valene da Silva Amarante Júnior ${ }^{4}$
\end{abstract}

\section{Introdução}

A suinocultura na grande Ilha de São Luís é uma atividade predominante de pequenas propriedades rurais tornando-se importante sob o ponto de vista social, econômico e, especialmente, como instrumento de fixação do homem no campo. Sendo constituída pela agricultura familiar e caracterizada pela pequena escala de produção.

Para os agricultores familiares há uma grande valorização da mão de obra familiar, além de oferecer o baixo investimento. As famílias produtoras de suínos, tanto vendem os leitões, como destina os machos em terminação para o abate. Enquanto os maridos cuidam da agricultura e dos animais maiores, as esposas tratam do rebanho de animais pequenos, e assim garante oportunidade de trabalho, renda e melhoria na qualidade de vida da família.

Visando este assunto o trabalho tem por objetivo orientar e capacitar os agricultores familiares de técnicas racionais de manejo na atividade suinícola focados nos aspectos relacionados à sanidade, nutrição e reprodução, suínos.

\section{Fundamentação Teórica}

Um dos desdobramentos mais imediatos da suinocultura é a recorrência de questões sobre a sanidade dos rebanhos e a segurança de oferta quantitativa e qualitativa do alimento produzido.

\footnotetext{
${ }^{1}$ Zootecnia, Universidade Estadual do Maranhão-UEMA, tielle.gf@gmail.com

${ }^{2}$ Mestranda em Ciência animal e Pastagem, Universidade Federal Rural de Pernambuco-UFRPE, raquel_lek@hotmail.com

${ }^{3}$ Zootecnia, Universidade Estadual do Maranhão-UEMA, claudenilde_123@hotmail.com

${ }^{4}$ Professor Doutor, Universidade Estadual do Maranhão, valenejr@yahoo.com.br
} 
Também é crescente o entendimento entre pesquisadores e extensionistas de que muitos problemas observados nessa atividade agropecuária decorrem da falta de investimento na medicina veterinária preventiva (MIELE, 2013).

No Brasil, existem granjas suinícolas que utilizam tecnologia avançada, apresentando níveis similares aos praticados nos países desenvolvidos. Porém incipiente atenção tem sido voltada à criação de suínos como uma atividade de subsistência familiar, apesar dessa, exercer papel de grande importância socioeconômica, sobretudo para os pequenos produtores rurais (SILVA FILHA et al., 2008).

A suinocultura local no Nordeste brasileiro é uma atividade muito importante no complexo socioeconômico dos agricultores e agricultoras familiares, não só pelos produtos desta criação como também por toda a situação socioeconômica vivenciada pelos criadores, além do prazer que sentem nesta atividade. (SILVA FILHA, 2009)

\section{Metodologia}

O projeto teve início no mês de outubro de 2015, no município de São Luís em comunidades de Cabral Miranda, Coquilho e Tajipuru. Para a identificação das referidas criações foram levantadas informações junto à Agência Estadual de Defesa Agropecuária do Maranhão (AGEDMA) e da Secretaria Municipal de Agricultura Pesca e Abastecimento - SEMAPA.

Inicialmente foram utilizados questionários semiestruturados envolvendo dados quantitativos e qualitativos, os dados obtidos dos questionários foram processados, seguidos de análise e interpretação. As informações foram armazenadas em bancos de dados do Excel. Por meio da ministração de palestras, e adoção de atividades práticas nas propriedades o presente projeto buscou-se orientar e capacitar os agricultores familiares de técnicas racionais de manejo ligadas as atividade suinícola.

\section{Resultados e Discussões}

O presente trabalho revelou que os produtores de suínos amostrados em áreas rurais do município de São Luís nos bairros do Tajipuru, Comunidade Cabral Miranda e Coquilho apresentam suas criações classificadas como de subsistência, sem tecnificação e envolvendo mão de 
obra familiar. Suptitz, Woberto e Hofer (2009) acreditam que o produtor precisa saber quais são os resultados obtidos, como melhorar as receitas e reduzir as despesas e como está a rentabilidade de sua atividade.

O quantitativo de suínos nas criações avaliadas variou de 15 a 250 animais, e $55 \%$ das propriedades tinham menos de 100 animais. Quanto ao manejo reprodutivo, $100 \%$ dos criadores adotam a monta controlada, o desmame é realizado aos: 30 dias (10\%), 40 dias (60\%) e acima dos 50 (40\%). Os animais de reposição são todos do mesmo plantel. Em relação ao manejo alimentar, $60 \%$ produz o alimento na própria propriedade e $40 \%$ adquire fora, a frequência da oferta do alimento é de: uma vez ao dia (60\%) e duas vezes (40\%). Dentre os alimentos ofertados: restos de comida (31\%), ração balanceada comercial $(21 \%)$ e ração balanceada na propriedade $(44 \%)$. Todos os criadores afirmaram realizar práticas sanitárias no manejo com os animais, afirmando ainda vacinar, realizar vermifugação, oferecer remédio de vermes, minerais e vitaminas. Dos problemas frequentes, há predominância de diarreias em leitões (50\%), sarnas (38\%) e verminoses (12\%). Os dados corroboram com as ideias de Lanfredi (2014) quando diz que o manejo é essencial na produção de suínos, o produtor precisa saber tratar os suínos, ter capacidade de organizar seu tempo, avaliar as prioridades, manter em dias os serviços de rotina, saber reconhecer as alterações do estado de saúde dos animais e propor soluções para os problemas.

O trabalho realizado identificou-se problemas ligados à criação de suínos, onde por meio de adoção de práticas de auxílio à produção e palestras foi possível demostrar alternativas para soluções dos mesmos, notou-se com essas atividades o interesse por parte dos produtores pela temática do projeto e uma preocupação com aumento na rentabilidade do negócio e sustentabilidade da atividade.

\section{Conclusões}

Percebeu-se que as pequenas criações de suínos analisadas no projeto apresentam um perfil de subsistência com baixo nível de tecnificação, emprego de manejo de forma rústica e mão de obra basicamente familiar. Nesse sentindo é necessário o estabelecimento de medidas de estímulo às pequenas criações na área estudada por meio de políticas públicas voltada aos produtores de suínos da região, requerendo sobre tudo, assistência técnica, orientações zootécnicas, educação sanitária para melhoria dos manejos, principalmente o manejo alimentar. 


\section{Referências}

LANFREDI, V. Suinocultura em uma propriedade rural: o retorno do investimento na suinocultura em uma propriedade rural. RAMVI, Getúlio Vargas, v. 01, n. 02, julh./ dez. 2014.

MIELE, M. Quais são as opções de política pública para enfrentar as sucessivas crises na suinocultura brasileira? Revista de Política Agrícola, Brasília, DF, v. 22, n. 1, p. 137-140, 2013.

SILVA FILHA, O. L.; PIMENTA FILHO, E. C.; SOUZA, J. F.; OLIVEIRA, A. S.; OLIVEIRA, R. J. F.; MELO, M.; MELO, L. M.; ARAÚJO, K. A. O.; SERENO, J. R. B. Caracterizaçãa do sistema de produção de suínos locais na microrregião do Curimataú Paraibano. Revista Brasileira de Saúde e Produção Animal, Ondina, v. 9, n. 1, p. 07-17, 2008.

SILVA FILHA, O.L.; ALMEIDA, M.J.O.; OLIVEIRA, R.J.F.; NOBRE, J.A. 2009. Criação de suínos locais no Estado do Piauí. Estudos iniciais. In: $\mathrm{X}$ Simposio Iberoamericano sobre Conservación y Utilización de Recursos Zoogenéticos. Palmira, Colombia, 11, 12 y 13 noviembre, 2009. Anais.

SÜPTITZ, Luciane Andréa Siedleski; WOBETO, Marciani Carla Rhoden; HOFER, Elza. Management costs in pig farming: a case study. Release for publication: 05/08/2009. Custos e @ gronegócio on line - v. 5, n. 1 - Jan/Apr - 2009. 